\title{
ANALISIS PENGARUH MEDIA SOSIAL TERHADAP LOYALITAS KONSUMEN DI SAYUR ORGANIK MERBABU
}

\author{
Bayu Murya*, Lasmono Tri Sunaryanto*, Hendrik Johannes Nadada*
}

\begin{abstract}
ABSTRAK
Sayuran Organik Merbabu adalah perusahaan yang bergerak di bidang agribisnis yang menjual produk sayuran segar berkualitas yang dihasilkan dari kebunnya sendiri. Produk sayuran sekarang mulai menjadi strategi pemasaran, Sayuran Organik Merbabu perlu memahami apa yang benar-benar diinginkan konsumen dan hal-hal apa yang mempengaruhi kepuasan konsumen ketika melakukan pembelian sayuran. Penelitian ini bertujuan untuk menganalisis pengaruh media sosial dan kualitas layanan terhadap kepuasan vegetable konsumen pada Sayuran Organik Merbabu. Jenis penelitian ini adalah metode survei deskriptif kuantitatif, Teknik pengambilan sampel menggunakan metode Non Probability Sampling dengan jumlah sampel yang digunakan sebanyak 108 responden. Teknik analisis data yang digunakan dalam analisis SEM (Structural Equation Modeling), yang dioperasikan melalui program IBM AMOS V.22. Hasil penelitian menunjukkan bahwa kualitas layanan memiliki pengaruh positif dan signifikan terhadap kepuasan pelanggan sonumer dalam Organic Merbabu Vagetables. Indikator signifikan membentuk faktor kualitas layanan termasuk kepercayaan, daya tanggap, jaminan, empati dan bukti fisik. Meskipun faktor media sosial menunjukkan hasil yang tidak signifikan dan berhubungan negatif, semua indikator yang membentuk seperti facebook, instagram dan whatsApp memiliki hasil yang signifikan di media sosial.
\end{abstract}

Kata kunci: Media Sosial, Kualitas Layanan, Kepuasan Pelanggan, Strategi Pemasaran

\begin{abstract}
Merbabu Organic Vegetable is company engaged in agribusiness that sells quality fresh vegetable products produced from its own garden. Vegetable products are now starting to be marketing strategies, Merbabu Organic Vegetables need to understand what consumers really want and what things effect consumer satisfaction when making vegetable purchases. This study aims to analyze the influence of social media and quality of service to the satisfaction of vegetable consumers in Merbabu Organic Vegetables.This type of research is quantitative descripyive survey method, The sampling technique uses The Non Probability Sampling method with the number of samples used as many as 108 respondents. The data analysis technique used in SEM ( Structural Equation Modeling ) analysis, which is operated through the IBM AMOS V.22 program. Results research shows that service quality has a positive and significant effect on sonsumer satisfaction of vegetables in Organic Merbabu Vagetables.Significant indicators shape service quality factors including trust, responsiveness, assurance, empathy and physical evidence. Although social media factors show insignificant results and are negatively related, all the indicators that form such as facebook, instagram and whatsApp have significant results on social media.
\end{abstract}

Keywords : Social Media, Service Quality, Customer Satisfaction, Marketing Strategy

\section{PENDAHULUAN}

Organik merupakan pertanian yang mengutamakn kelestarian alam yang berkelanjutan yang seluruh proses pengaplikasiannya harus sesuai dengan aturan yang sudah ditetapkan dan 
diresmikan oleh pemerintah sesuai acuan di dalam SNI. Sudah menjadi ketentuan bagi seluruh pelaku usaha yang bergerak di sektor pertanian organik, di Indonesia sayuran merupakan komoditas pertanian yang sangat digemari masyarakat dan merupakan kebutuhan yang sangat penting untuk kesehatan. Salah satu usaha untuk memenuhi kebutuhan konsumsi sayuran domestik, selain peningkatan produktivitas, dibutuhkan pula kinerja pemasaran yang efektif. Konsumen cenderung menyukai produk sayuran dalam keadaan segar, oleh karena itu sayuran harus segera didistribusikan kepada konsumen guna meminimalkan terjadinya penurunan kualitas. Perubahan gaya hidup modern yang terjadi sekarang ini, turut berpengaruh terhadap pembelian sayuran segar. Menurut Sunaryanto (2013) berpendapat bahwa salah satu kunci keberhasilan untuk mencapai kepuasan konsumen adalah menerapkan prinsip 2Q $+2 \mathrm{C}$ yaitu Quality (kualitas), Quantity (jumlah), Continuity (kontinuitas) dan Conformty (keseragaman). Konsumen yang sebelumnya membeli sayuran segar di pasar tradisional mulai beralih ke pasar modern (pasar online) dengan berbagai pertimbangan. Menurut Engel dan Paul (2001) menyatakan bahwa "Kepuasan konsumen hanya dapat dicapai apabila perusahaan mampu memberikan kualitas barang maupun jasa yang baik kepada konsumen". Diantaranya, tidak perlu menawar harga, kelengkapan produk, serta jaminan atas kualitas produk dan layanan. Perusahaan masa kini berusaha kuat mempertahankan pelanggannya, mereka sadar bahwa biaya menarik satu pelanggan baru bisa lima kali dari biaya mempertahankan pelanggan yang ada. Apabila konsumen menaruh sikap positif dalam evaluasi pembeliannya, maka tercipta kepuasan dan loyalitas konsumen untuk melakukan pembelian ulang. Supranto, Johannes. (2011). Pengukuran
Tingkat Kepuasan Pelanggan Untuk Menaikkan Pangsa Pasar.

Sayur Organik Merbabu (SOM) adalah perusahaan yang menjual produk sayuran segar berkualitas yang diproduksi dari kebun sendiri. Sayur Organik Merbabu (SOM) mempunyai sebuah unit, yang menangani bagian pemasaran sayuran, Sayuran yang dipasarkan di Sayur Organik Merbabu (SOM) rata-rata masih dalam keadaan segar dan mempunyai kualitas yang cukup tinggi, karena telah melewati proses grading dan pengemasan sebelum dipasarkan di pasarkan.

Produk sayuran saat ini mulai tersedia di berbagai tempat berbelanja, namun penjualannya belum terlalu meningkat. Adanya supermarket dan pasar modern (pasar online) yang juga menjual sayuran segar menjadi pesaing bisnis bagi Sayur Organik Merbabu (SOM) dalam memasarkan produknya. Untuk dapat memenangkan persaingan pasar, pihak Sayur Organik Merbabu (SOM) perlu memahami apa yang sebenarnya diinginkan oleh konsumen dan hal-hal apa saja yang mempengaruhi kepuasan konsumen saat melakukan pembelian sayuran. Menurut Thoyibie (2010), media sosial adalah konten berisi informasi, yang dibuat oleh orang yang memanfaatkan teknologi penerbitan, sangat mudah diakses dan dimaksudkan untuk memfasilitasi komunikasi, pengaruh dan interaksi dengan sesama dan dengan khalayak umum.

Dari latar belakang diatas maka dapat dirumuskan permasalahan yang ada di Sayur Organik Merbabu (SOM) sebagai berikut: Bagaimanakah pengaruh media sosial dan kualitas layanan terhadap kepuasan konsumen sayuran di Sayur Organik Merbau (SOM)?

Berdasarkan konsep penelitian diatas, maka dapat dirumuskan hipotesis sebagai berikut: Adanya hubungan antara media sosial dan loyalitas konsumen dengan kepuasan konsumen di Sayur Organik Merbabu (SOM). 


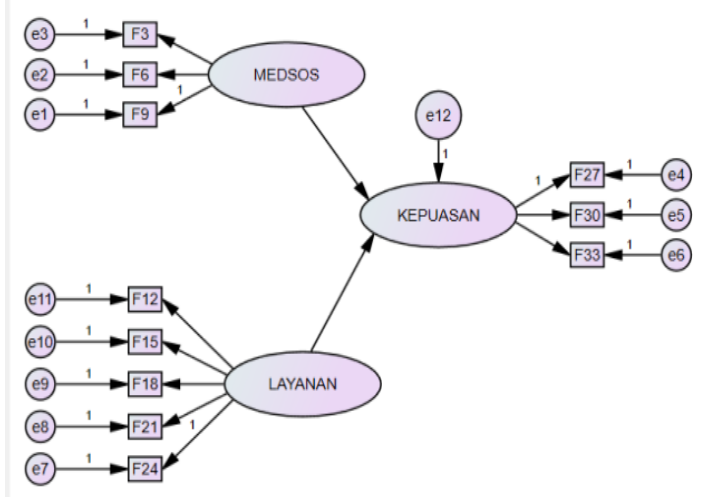

Gambar 1. Model Penelitian

\section{METODOLOGI PENELITIAN}

\section{Bahan dan Metode}

Tempat Sayur Organik Merbabu (SOM) Sidomukti RT 005/RW 005, Getasan, Kopeng, Kabupaten Semarang, Jawa Tengah. Data yang dikumpulkan dalam penelitian ini ada dua yaitu data primer dan sekunder. Data primer diperoleh dari kuisioner online dangan memanfaatkan media sosial yang berpedoman pada instrumen penelitian berupa kuesioner. Sedangkan data sekunder merupakan jenis data yang diperoleh secara tidak langsung, melalui literatur, jurnal penelitian ataupun dokumen yang sekiranya diperlukan untuk penyusunan penelitian.

Daftar pertanyaan yang diajukan pada responden berupa daftar pertanyaan tertutup dan terbuka. Daftar pertanyaan tertutup digunakan untuk mendapatkan data tentang variabel-variabel yang diukur dalam penelitian ini. Sedangkan daftar pertanyaan terbuka digunakan untuk mendapatkan informasi tentang karakteristik responden.

Instrumen penelitian menggunakan skala likert dengan skala 1-5. Penarikan sampel menggunakan metode Non Probability Sampling, dengan cara ini semua elemen populasi belum tentu

memiliki peluang yang sama untuk menjadi anggota sampel. Artinya, pengambilan sampel didasarkan pada kriteria tertentu seperti judgment, status, kuantitas, kesukarelaan, dan sebagainya (Sugiyono,2013). Jumlah sampel yang

akan digunakan dalam penelitian ini adalah 108 orang. Ferdinand (2002) menyatakan bahwa ukuran sampel untuk analisis SEM yang sesuai berkisar antara 100-200. Teknik analisis data yang digunakan adalah analisis model persamaan struktural SEM (Structural Equation Modeling) dengan menggunakan program komputer SPSS 20.0 dan program IBM AMOS (Analysis of Moment Structure) 22.0.

Tabel 1. Goodness of Fit Index

\begin{tabular}{ccccc}
\hline No & Indeks & Nilai Kritis & $\begin{array}{c}\text { Hasil } \\
\text { Analisis }\end{array}$ & Evaluasi \\
\hline 1 & Chi square & $\begin{array}{c}\text { Diharapkan } \\
\text { kecil }\end{array}$ & 134,027 & Baik \\
2 & Probabilitas & $\geq 0,05$ & 0,000 & Kurang Baik
\end{tabular}




$\begin{array}{llccc}3 & \text { CMIN/DF } & <2,00 / 3,00 & 3,191 & \text { Kurang Baik } \\ 4 & \text { GFI } & \geq 0,90 & 0,844 & \text { Baik } \\ 5 & \text { AGFI } & \geq 0,90 & 0,755 & \text { Cukup Baik } \\ 6 & \text { RMSEA } & \leq 0,08 & 0,143 & \text { Kurang Baik } \\ 7 & \text { TLI } & \geq 0,90 & 0,813 & \text { Cukup Baik } \\ 8 & \text { CFI } & \geq 0,90 & 0,857 & \text { Baik } \\ 9 & \text { NFI } & \geq 0,90 & 0,808 & \text { Cukup Baik }\end{array}$

Sumber: Data primer yang diolah (2019)

\section{HASIL DAN PEMBAHASAN}

\section{Karakteristik Responden}

Karakteristikn responden menggambarkan keadaan responden pada penelitian ini. Gambaran umum responden merupakan hasil persebaran kuisioner terhadap konsumen yang sudah melakukan pembelian sayuran di Sayur Organik Merbabu (SOM) dari 108 responden yang merupakan sampel dalam penelitian memiliki gambaran

karakterisk sebagai berikut: Sebagian besar responden yang melakukan pembelian sayuran di Sayur Organik Merbabu (SOM) didomonasi oleh perempuan yaitu sebanyak 70 orang atau sebesar $64,8 \%$.

Ditinjau dari segi usia, terlihat bahwa responden dengan rentan usia 19-28 tahun adalah responden terbanyak dengan presentase sebesar 87,1 \%. Sedangkan dilihat dari segi pendidikan lebih didominasi oleh lulusan SMK/SMA sebesar 60,2\%. Dari segi banyaknya Pembelian konsumen sayuran organik terbanyak adalah 4 kali atau sebesar 35,2 $\%$ dari total responden yang ada.

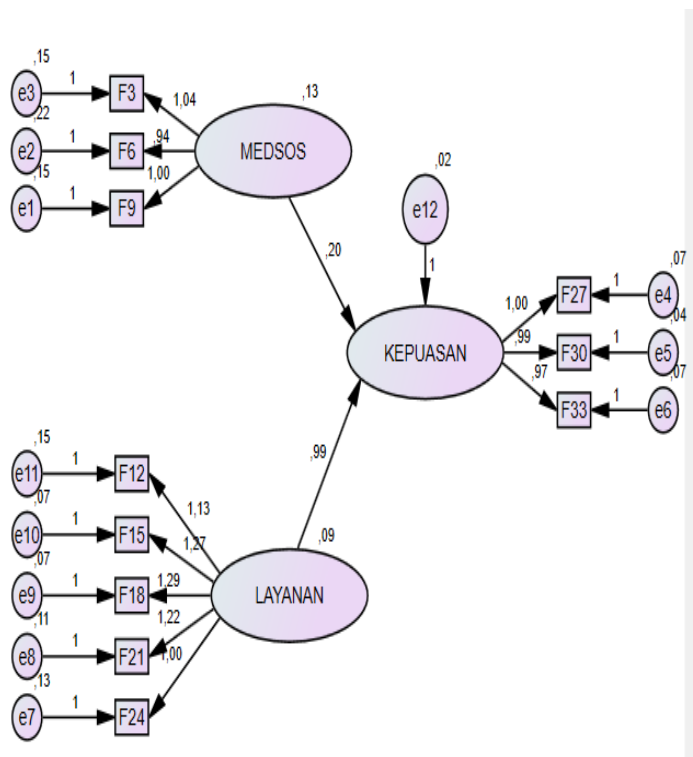

Gambar 2. Factor Loading Amos

\section{Analisis Hubungan Antara Indikator Dengan Variabel Nilai Factor Loading}

Dari hasil pemodelan dapat dilihat berdasarkan nilai factor loading seperti yang ditunjukkan pada Gambar 2. Sedangkan dasar dari pengambilan keputusan adalah sebagai berikut:

- Jika factor loading > 0,50 maka H0 diterima.

- Jika factor loading $<0,50$ maka H0 ditolak.

Perolehan nila factor loading dari hubungan anatara indikator dengan 
variabel atas nilai indikator media sosial F3, F6, F9 dapat di terima karena nilai lebih dari 0,50 sedangkan indikator kualitas layanan F12, F15, F18, F21, F24 juga dapat diterima nila yang di hasilkan lebih dari 0,50 dan yang terakhir indikator yang mempengaruhi kepuasan konsumen F27, F30, F33 juga dapat diterima karena nilai lebih dari 0,50 jadi dari hasil olah data dengan amos keseluruhan hubungan indikator dengan variabel dapat di terima dan memenuhi sarat.
Sedangkan untuk nila factor loading antar variabel media sosial sebesar 0,20 tidak dapat diterima karena nilai factor loading di bawah 0,50. Untuk nilai factor loading kualitas layanan sebesar 0,99 nilai dapat di terima karena di atas 0,50. Pada sebagian besar refrensi bobot faktor sebesar 0,50 atau lebih dianggap memiliki validasi yang cukup kuat untuk menjelaskan konstruk laten (Hair et al,1996; Ferdinand,2000) menjelaskan bahwa loading factor paling lemah yang dapat diterima adalah 0,40 .

Tabel 2. Hubungan antar Variabel

\begin{tabular}{lrrrrc}
\hline \multicolumn{1}{c}{ Variabel } & Estimate & S.E. & C.R. & P & Keterangan \\
\hline Kepuasan <---Medsos &, 196 &, 078 & 2,515 &, 012 & Tidak \\
Kepuasan <--- K. Layanan &, 991 &, 157 & 6,301 & $* * *$ & Signifikan \\
& Signifikan \\
\hline
\end{tabular}

Sumber : : Data primer yang diolah (2019)

Keterangan : Standardized estimates menunjukan koefisien estimasi

\section{Pengaruh Media Sosial Terhadap Kepuasan Konsumen Sayuran di Sayur Organik Merbabu (SOM)}

Berdasarkan Tabel 2. terlihat bahwa indikator X1 (media sosial) memiliki nilai C.R sebesar 2,515< 2,576, yang berarti bahwa indikator X1 (media sosial) tidak memiliki pengaruh dengan tingkat signifikansi $90 \%$ terhadap variabel kepuasan konsumen. Untuk factor loading indikator X1 (media sosial) diperoleh nilai sebesar 0,196 yang berarti korelasinya sangat lemah, walaupun nilai probabilitasnya lebih dari $5 \%$ hal ini tidak dapat diterima, sehingga dapat disimpulkan bahwa indikator X1 (media sosial) tidak berpengaruh signifikan terhadap kepuasan konsumen. Hasil analisis yang didapat menunjukkan bahwa media sosial tidak berpengaruh signifikan terhadap kepuasan konsumen sayuran organik di Sayur Organik Merbabu (SOM). Dengan internet pemasaran produk dapat lebih terbantu, karena internet memungkinkan proses pemasaran yang lebih efektif, respon yang lebih cepat dan biaya yang lebih murah (Hermawan, 2012).

\section{Pengaruh Kualitas Layanan terhadap Kepuasan Konsumen Sayuran di Sayur Organik Merbabu (SOM)}

Berdasarkan Tabel 2. terlihat bahwa Indikator X2 (kualitas layanan) memiliki nilai C.R sebesar 6,301 > 2,56, yang berarti bahwa indikator X2 memiliki pengaruh dengan tingkat signifikansi $99 \%$, hal ini ditandai juga dengan tanda tiga bintang pada kolom probabilitas. Indikator X2 memiliki nilai factor loading sebesar 0,991 yang berarti korelasinya kuat. Berdasarkan hasil yang diperoleh dapat disimpulkan bahwa indikator X2 berpengaruh signifikan terhadap kepuasan konsumen. Hasil analisis data menunjukkan bahwa kualitas layanan berpengaruh signifikan terhadap kepuasan konsumen sayuran organik di Sayur Organik Merbabu (SOM). Hal ini menunjukkan bahwa Sayur Organik Merbabu (SOM) telah mampu 
memberikan pelayanan yang baik bagi konsumennya. Hasil analisis yang didapat sejalan dengan apa yang dikemukakan dalam penelitiannya yang menyatakan bahwa kualitas layanan memiliki pengaruh positif terhadap kepuasan konsumen. Sesuai dengan teori yang dikemukakan oleh Goetsch dan Davis (1994) dalam Sari (2016) kualitas layanan merupakan suatu kondisi dinamis yang berhubungan dengan produk jasa, manusia, proses, dan lingkungan yang mampu memenuhi dan atau melebihi harapan konsumen.

Artinya semakin baik kualitas pelayanan yang diberikan kepada konsumen, maka akan semakin tinggi tingkat kepuasan konsumen terhadap Sayur Organik Merbabu (SOM), dan sebaliknya semakin buruk kualitas pelayanan yang diberikan maka akan semakin rendah pula tingkat kepuasan konsumen terhadap Sayur Organik Merbabu (SOM). Menurut Kotler dan Amstrong (2007) dengan mengetahui tingkat kepuasan konsumen, perusahaan dapat melakukan antisipasi harapan konsumen terhadap suatu produk. Harapan tersebut kemudian dibandingkan dengan kinerja produk sehingga membentuk dua kondisi, yaitu kepuasan atau ketidakpuasan. tersebut menunjukan bahwa tidak semua hipotesis yang dianjukan dapat diterima. Hipotesis yang terbukti secara signifikan adalah hipotesis hubungan konstruk kualitas layanan terhadap faktor kepuasan konsumen. Sementara hipotesis hubungan konstruk media sosial terhadap faktor kepuasan konsumen menunjukan bukti tidak signifikan.

\section{KESIMPULAN}

Media Sosial tidak berpengaruh positif dan signifikan terhadap kepuasan konsumen sayuran di Sayur Organik Merbabu (SOM). Hasil analisis yang didapat menunjukkan bahwa Sayur Organik Merbabu (SOM) belum mampu memenuhi dari segi pelayanan media sosial, konsumen merasa belum puas karena tidak sesuai yang mereka inginkan, belum terpenuhi ketika berbelanja sayuran di Sayur Organik Merbabu (SOM). Kualitas pelayanan berpengaruh positif dan signifikan terhadap kepuasan konsumen sayuran di Sayur Organik Merbabu (SOM). Artinya semakin baik kualitas pelayanan yang diberikan kepada konsumen, maka akan semakin tinggi tingkat kepuasan konsumen terhadap Sayur Organik Merbabu (SOM), dan sebaliknya semakin buruk kualitas pelayanan yang diberikan maka akan semakin rendah pula tingkat kepuasan konsumen terhadap Sayur Organik Merbabu (SOM).

\section{DAFTAR PUSTAKA}

Engel, J. F. dan Paul, M. 2001. Perilaku Konsumen. Penerbit Binarupa Aksara. Jakarta.

Ferdinand, A. 2000. Structural Equation Modelling dalam penelitian manajemen. BP Undip.

Ferdinand, Augusty. 2002. Structural Equation Modelling dalam Penelitian Manajeman. Penerbit FE UNDIP. Semarang

Hermawan, Agus. 2012. Komunikasi Pemasaran. Penerbit Erlangga. Jakarta.

Kotler, P dan Amstrong, G. 2007. Prinsip-Prinsip Pemasaran. Edisi Bahasa Indonesia. Jilid 1. Penerbit Erlangga. Jakarta.

Sari, D. D. 2016. Analisis Kualitas Produk, Kualitas Layanan Dan Harga Terhadap Kepuasan Konsumen (Studi Kasus Pada Konsumen SIM Card GSM Prabayar XL di Kota Yogyakarta). Skripsi. Fakultas Ilmu Ekonomi, Universitas Negeri Yogyakarta. Yogyakarta.

Sugiyono. 2013. Metode Penelitian Kuantitatif, Kualitatif dan $R \& D$. Penerbit Alfabeta. Bandung. 
Supranto, Johannes. 2011. Pengukuran Tingkat Kepuasan Pelanggan Untuk Menaikkan Pangsa Pasar. Penerbit Rineka Cipta. Jakarta.

Sunaryanto, L.T. 2013. Pengantar Ilmu Pertanian. Penerbit FPB UKSW. Salatiga.
Thoyibie, L. 2010. Psikologi Social Media. http://komunikasiindonesia.org.

*Dosen SKU Universitas Tadulako (Email: bayumurya2019@gmail.com) 